Special Issue: Defaunation's impact in tropical terrestrial ecosystems

\title{
Ecological erosion of an Afrotropical forest and potential consequences for tree recruitment and forest biomass
}

\author{
John R. Poulsen a,*, Connie J. Clark ${ }^{\mathrm{a}}$, Todd M. Palmer ${ }^{\mathrm{b}}$ \\ ${ }^{a}$ Nicholas School of the Environment, Duke University, P.O. Box 90328, Durham, NC 27708, United States \\ ${ }^{\mathrm{b}}$ Department of Biology, University of Florida, P.O. Box 118525, Gainesville, FL 32611, United States
}

\section{A R T I C L E I N F O}

\section{Article history:}

Received 29 September 2012

Received in revised form 7 March 2013

Accepted 12 March 2013

Available online $\mathrm{xxxx}$

\section{Keywords:}

Central Africa

Defaunation

Seed dispersal

Seed predation

Herbivory

Above-ground biomass

\begin{abstract}
A B S T R A C T
Unprecedented rates of logging and hunting threaten to transform the remaining primary tropical forest into a degraded mosaic, emptied of wildlife. Defaunation is expected to interrupt plant-animal interactions with cascading effects for forest structure, composition, and ecosystem services. In a Central African forest first logged 35 years ago, we evaluated this process of ecological erosion in 30 study sites distributed across forest disturbed by logging and hunting, logging alone, and neither logging nor hunting. Both logging and hunting tended to reduce abundances of large mammals, together shifting the relative abundance of the animal community towards squirrels and small birds. Through a series of experiments, we evaluated the effects of logging and hunting on seed dispersal, seed predation and herbivory. We demonstrate that complete defaunation is not necessary to significantly alter the strength of plant-animal interactions. Hunting reduced the mean dispersal distances of nine mammal-dispersed tree species by $22 \%$. Rates of seed predation were similar among forest types, but hunted forest had significantly lower rates of herbivory that we attribute to the lower abundance of mesoherbivores. Hunted forest also had significantly lower above-ground biomass $\left(301 \mathrm{Mg} \mathrm{ha}^{-1}\right)$ than the logged only ( $358 \mathrm{Mg} \mathrm{ha}^{-1}$ ) and undisturbed ( $455 \mathrm{Mg} \mathrm{ha}^{-1}$ ) forest types, but similar numbers of tree species and individuals. Lower biomass in hunted forest is likely attributable to significantly lower wood densities at small tree size classes $(<40 \mathrm{~cm})$. We hypothesize that over time the human-mediated modification of plant-animal interactions can alter the composition of the forest to have a higher proportion of fast-growing, low wood density tree species, diminishing the long-term potential for carbon storage.
\end{abstract}

(c) 2013 Elsevier Ltd. All rights reserved.

\section{Introduction}

Worldwide, tropical forests are being emptied of their large vertebrate populations (Brook et al., 2003; Fa et al., 2003; Peres and Palacios, 2007). Defaunation, the local extirpation of large vertebrates, is driven by myriad activities, including rural population growth, artisanal mining, logging and road construction; but the proximate factor is overhunting. Subsistence and commercial hunting take an enormous toll on populations of tropical mammals, birds and reptiles, with annual losses of animals estimated at 6 million in Southeast Asia, 16 million in the Brazilian Amazon, and 18 million in Central Africa (Butler, 2013).

It is widely recognized that losses of vertebrate populations can disrupt plant-animal interactions, threatening the integrity of natural ecosystems. Hunting can alter rates of pre-dispersal predation (Beckman and Muller-Landau, 2007), seed dispersal (Wright et al.,

\footnotetext{
* Corresponding author. Tel.: +1 919668 4060; fax: +1 9196848741.

E-mail addresses: john.poulsen@duke.edu (J.R. Poulsen), connie.j.clark@duke.edu (C.J. Clark), tmp@ufl.edu (T.M. Palmer)
}

2000; Galetti et al., 2006; Brodie et al., 2009; Holbrook and Loiselle, 2009), seed predation (Wright et al., 2000, 2007a,b), seedling predation (Vanthomme et al., 2010), and herbivory (Dirzo and Miranda, 1991). Changes in these processes should have cascading effects for species composition, diversity, and structure of plant communities (Muller-Landau, 2007; Wright et al., 2007a,b). One of the few generalizations to have emerged from these studies is the prediction that defaunation will be most detrimental for large-seeded tree species (Kurten, this issue); however there is disagreement over the consequences of these changes for the plant community (e.g., Wright et al., 2007a,b; Vanthomme et al., 2010). While the short-term responses of forests to hunting are beginning to be understood, the long-term ecological consequences remain a matter of speculation.

Defaunation in Central Africa would probably be a localized problem if not for extractive industries whose operations take place over millions of hectares (Butler and Laurance, 2008; Clark and Poulsen, 2012). With deeper roots than other industries, timber extraction is a good example of how large-scale extractive industries set the stage for defaunation. Logging operations open 
roads and provide access for slash-and-burn farmers and hunters to remote forests (Wilkie et al., 2000; Robinson et al., 1999). Logging requires a labor force to inventory, extract, and refine logs; thus villages and towns are built in the forest, increasing hunting pressure on wildlife (Poulsen et al., 2009).

Defaunation generally occurs in size-based increments, with hunters first taking the largest species, and then working down to lower size classes of animals (Peres and Palacios, 2007; Poulsen et al., 2011); most Central African forests are located somewhere between the extremes of complete defaunation and a fully intact vertebrate community. Hunting therefore initiates a process we call ecological erosion - the incremental deterioration or alteration of ecological communities and processes. This term captures the nature of the phenomenon, as most interactions are not completely lost, but rather eroded and weakened as the animal community is modified. The degree of change for plant-animal interactions and the plant community will depend on the intensity of hunting and sensitivity of the faunal community. This raises questions of whether: (1) different disturbances, such as logging and hunting, impact animal guilds in different ways and potentially offset each other's negative effects on wildlife; and (2) whether ecological processes are maintained in the absence of complete defaunation.

In this paper, we evaluate the potential consequences of ecological erosion for the species composition and structure of a Central African forest. We synthesize the results of several experiments conducted across a gradient of hunting and logging in Republic of Congo. Intensive hunting in the area likely began with the onset of logging 35 years before this study: its effects are now manifested by significantly higher abundances of small-bodied species in disturbed forest compared to undisturbed forest (Poulsen et al., 2011). We examine the effects of reduced populations of large-bodied species on ecological processes by comparing (1) seed rain abundance and seed dispersal patterns, (2) post-dispersal seed predation, and (3) herbivory among forest disturbed by logging and hunting, logging alone, and neither logging nor hunting. To assess the possible repercussions of changes to ecological processes, we compare tree species composition and biomass among forest types.

\section{Materials and methods}

\subsection{Study site description and design}

In 2005, we initiated a research program to monitor the impact of logging and hunting on tropical forest dynamics in Republic of Congo (Clark et al., 2009; Poulsen et al., 2009, 2011; Fig. 1). This area includes the Nouabalé-Ndoki National Park (NNNP) and the adjacent Kabo logging concession (KLC) managed by the Congolaise Industrielle des Bois company (CIB). The NNNP has never been commercially logged and has not recently contained permanent villages; although hunter-gatherer populations inhabited the region for approximately 40,000 years and evidence of iron smelting sites and burning date from $1240 \mathrm{BP}$ (Lanfranchi et al., 1998; Brncic et al., 2007). The KLC was first selectively logged ( $<2$ trees/ha) approximately 35 years before our study. We estimate that the effects of both hunting and logging likely date back this long, as logging operations included the construction of a worker's camp ( 3000 people in 2005) and a sawmill at Kabo village (CIB, 2006).

As part of this research program, we established the Sangha Plot Network (SPN) consisting of 30 sites in an area of $3000 \mathrm{~km}^{2}$ (Fig. 1). Each site includes a 1-ha tree plot for measuring forest diversity and structure at the midpoint of a $2.5 \mathrm{~km}$ transect for quantifying animal densities. The SPN stretches over a gradient of undisturbed forest to logged, hunted forest near the town of Kabo. We randomly located the sites in mixed lowland tropical forest within each of the three different forest types: logged and hunted forest, logged and unhunted forest, and unlogged and unhunted forest (see Poulsen et al. (2011) for details). Here we refer to the forest types as "hunted", "logged only" and "undisturbed".

None of our study sites are defaunated: they all retain the full complement of forest species, but at different densities, with the hunted site on a trajectory to defaunation. Although hunting and logging can sometimes impact animal guilds in different ways (logging reduced the density of squirrels, whereas hunting increased densities of squirrels), when combined they exacerbated declines in populations of medium- and large-bodied mammals and shifted the relative abundance of the community towards small-bodied squirrels and birds (Fig. 2, Poulsen et al., 2011). Elephants were an exception to this pattern: their densities did not differ significantly between hunted and undisturbed forests. We attribute this to active law enforcement efforts to protect elephants and logginginduced habitat modification (Clark et al., 2009). Elephant densities were highest in logged only forest, probably because the opening of forest during timber extraction results in a surge of seedling and saplings that are browse for elephants (Clark et al., 2009). However, our snapshot of the animal community, conducted 5 years after the creation of an armed eco-guard unit, likely does not represent the history of the area. In the past, poaching of elephants for ivory was intense in large forest clearings: elephant carcasses were often seen in clearings during fly-overs in the1990s (B. Curran, pers. comm.). That is to say, we believe that elephant populations were lower in the past (maybe substantially so), particularly in the hunted forest, and this may have contributed to present day differences in forest structure.

We designed our study to detect the individual effects of logging, hunting, and the combination of logging and hunting. We estimate these effects for different responses (e.g., animal density, seed dispersal distances) by comparing the value at the disturbed site from the value where that disturbance was not present:

$$
\begin{aligned}
& \text { Effect }_{l}=\text { Site }_{l, u h} / \text { Site }_{u l, u h} \\
& \text { Effect }_{h}=\text { Site }_{l, h} / \text { Site }_{l, u h} \\
& \text { Effect }_{l+h}=\text { Site }_{l, h} / \text { Site }_{u l, u h}
\end{aligned}
$$

where subscript "l" indicates logged, subscript "h" indicates hunted, subscript "uh" indicates unhunted, and subscript "ul" represent unlogged. Note that due to the missing forest type (unlogged, hunted), our estimate of the effect of hunting is actually the estimate of hunting in logged forest.

\subsection{Seed rain and dispersal}

To determine the impact of changes in the vertebrate community on seed rain patterns, we erected $21-1 \mathrm{~m}^{2}$ seed traps in each forest plot ( $N=630$ traps in 30 plots). Seed traps were constructed of plastic mesh attached to $1 \times 1 \mathrm{~m}$ wooden frames elevated to a height of $1 \mathrm{~m}$ from the ground. Traps were centered along three lines at 25,50 , and $75 \mathrm{~m}$ from the plot border, with $10 \mathrm{~m}$ separating each trap so that all traps were at least $20 \mathrm{~m}$ from the plot borders. During the two-year duration of this study, we collected all seeds and fruits that fell into the traps every two weeks and counted and identified them to species.

To estimate seed dispersal patterns across the three forest types, we used an inverse modeling method that models the density of seeds at a single location (seed trap) as the summed contribution of seeds dispersed from all conspecific adult trees in the plot. We assumed that the contribution of each adult tree to the seed rain at a location depends only on its individual fecundity 


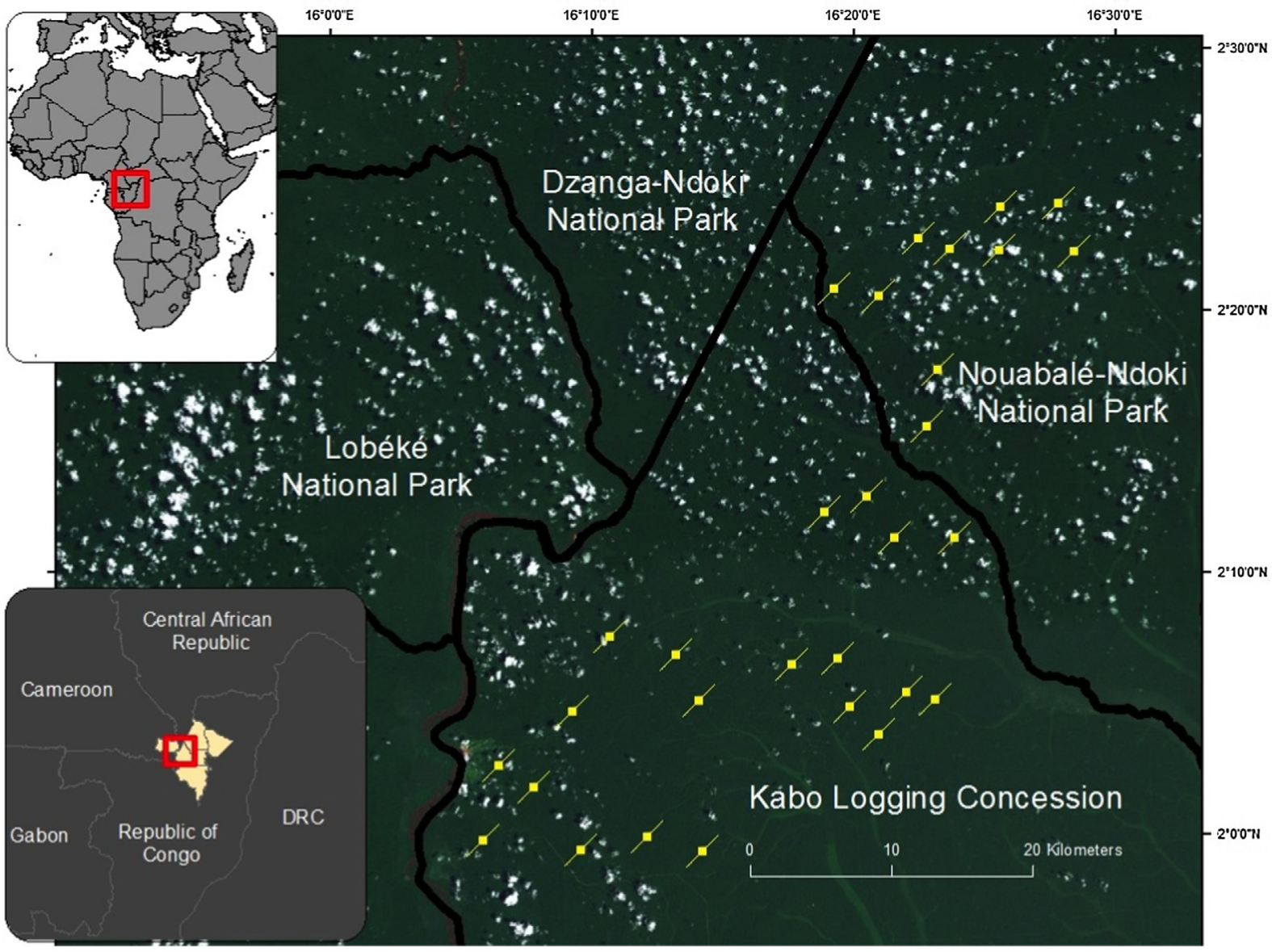

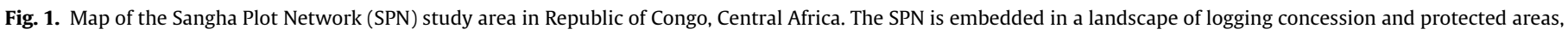

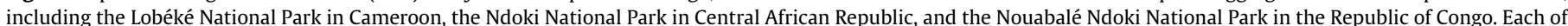

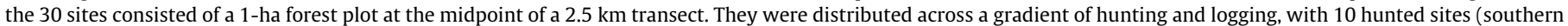

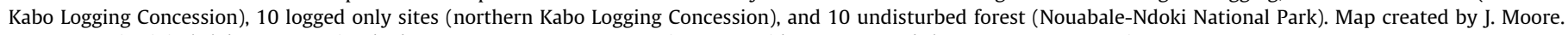
Sources: Esri, DigitalGlobe, GeoEye, i-cubed, USDA, USGS, AEX, Getmapping, Aerogrid, IGN, IGP, and the GIS User Community.

and its distance to the seed trap. Our approach parallels methods in Ribbens et al. (1994) for modeling the dispersion of seedlings, but adapted for modeling seed dispersal (Clark, 1998; Sagnard et al., 2007; Muller-Landau et al., 2008).

The number of seeds $N_{i j}$ in seed trap $i$ in plot $j$ is the sum over each adult $k$ of the product of its fecundity $F_{k}$ by the dispersal kernel $f$ which gives the probability that a seed is dispersed at a distance $d_{i k}$ from a tree:

$$
N_{i j}=\sum_{i j} F_{k} f\left(d_{i k}\right)
$$

We modeled adult fecundity by scaling seed production to tree size, $F_{k}=b s_{k}^{\beta}$, where the number of seeds produced by a tree $\left(F_{k}\right)$ is the size (diameter-at-breast height: $\mathrm{dbh}$ ) $s_{k}$ scaled by $\beta$ which controls the dependence of fecundity on size and $b$ is a proportionality constant. We considered dispersal to be isotropic and modeled the seed shadow as a negative exponential dispersal kernel, $f(x)=\gamma$ $\exp \left(-d_{i k} / \alpha\right)$. Here $\gamma$ is a normalizer that controls overall seed density by constraining the dispersal kernel between 0 and 1 $\left(\gamma=\int_{d=0}^{d=\infty} e^{-d_{i k} / \alpha}\right), \alpha$ is scale of dispersal.

We assumed that the observed number of seeds in a seed trap followed a negative binomial error distribution with clumping parameter $\kappa$ (Hilborn and Mangel, 1997; Clark, 1998). We calibrated parameters for the dispersal model by searching numerically for the combination of parameter values that maximize the likelihood function, using the L-BFSG-B method (Byrd et al., 1995).

\subsection{Seed predation and herbivory}

To evaluate the strength of seed predation, herbivory and seedling recruitment at each site, we conducted caged and uncaged seed addition experiments. We established 63 stations in 7 randomly chosen plots from each forest type. In each station, we sowed seeds of five randomly selected tree species: Pancovia laurentii, Staudtia kamerunensis, Manilkara mabokeensis, Myrianthus arboreus, and Entandophragma utile. Species were chosen from a list of all tree species for which we recorded at least five seeds in the first year of seed rain ( $N=277$ species). This allowed us to collect sufficient numbers of seeds to conduct the experiment, while not biasing selection towards any particular species characteristic. The five focal species vary in regeneration niche, dispersal mode, seed size, and relative abundance, and adult individuals of all species co-exist across the study site (Clark et al., 2012).

We divided each $6 \times 10 \mathrm{~m}$ station into $60,0.5 \times 0.5 \mathrm{~m}$ quadrats with $0.5 \mathrm{~m}$ between each quadrat to provide access by researchers ( $N=3,780$ quadrats). In each quadrat we scattered seeds of one species in one of seven densities $(0,25,50,100,200,500$, and 2000 times the average species-specific natural seed rain density; $N=46,620$ seeds). Following seed addition, we monitored seedling emergence and mortality every 3 months for 2 years. At each observation period, we recorded the height, condition, and number of leaves of each seedling. To quantify the strength of terrestrial vertebrate seed predation and herbivory, we established caged treatments within all stations for three of the five focal species 

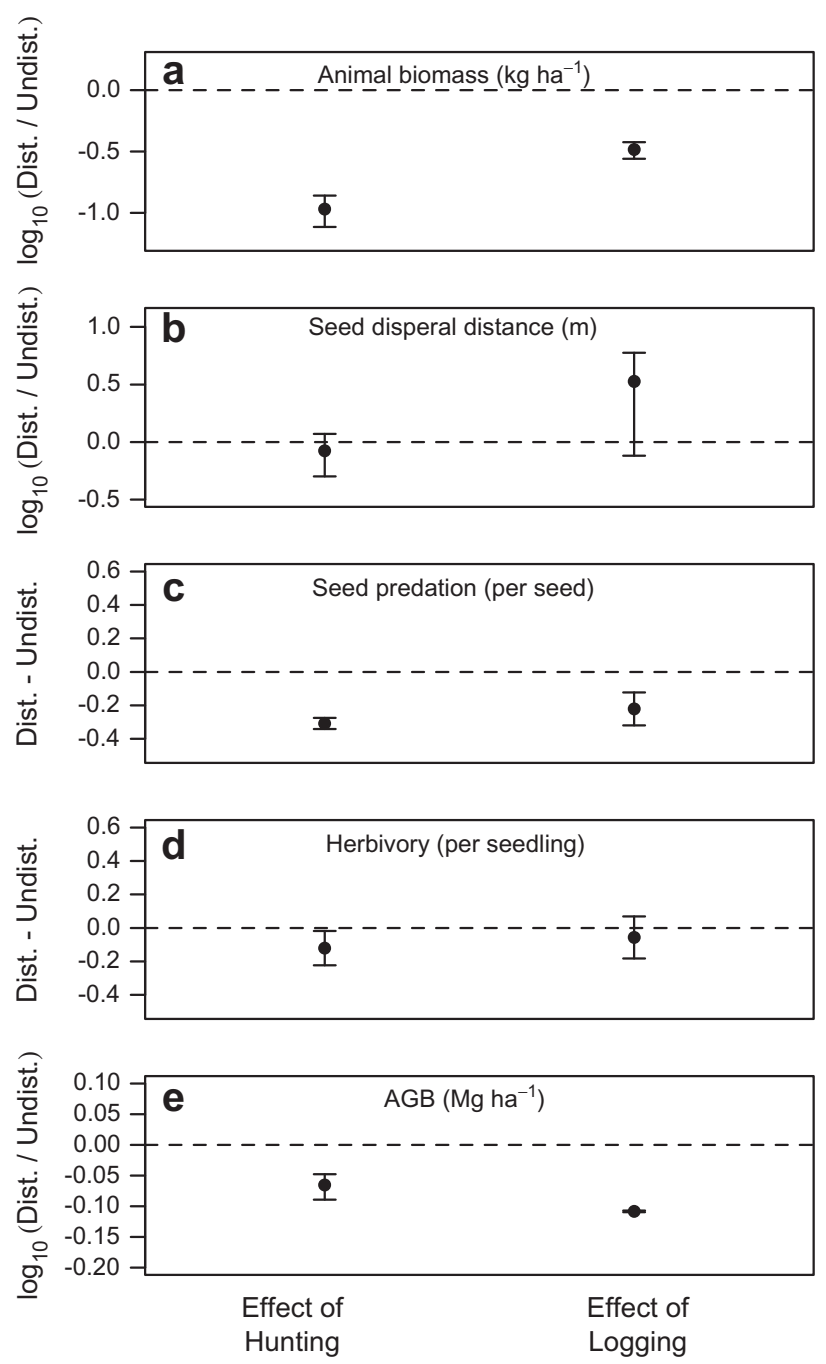

Fig. 2. Effects of hunting and logging on (a) biomass of medium- and large-bodied animals, (b) mean seed dispersal distance, (c) rates of seed predation, (d) rates of herbivory, and (e) forest biomass. For animal biomass, seed dispersal, and forest biomass, the effects of disturbance were estimated as log ratios by dividing the value of the disturbed sites from the value of the sites where that disturbance was not present (e.g., Effect ${ }_{h}=\log _{10}\left(\right.$ Site $_{h, l} /$ Site $\left._{u h, l}\right)$, where subscripts define disturbance type [h, hunting; uh, unhunted; l, logged]). For rates of seed predation and herbivory, the effects of disturbance were estimated as the difference between the value of the disturbed sites from the value of the sites where that disturbance was not present. Bars represent $95 \%$ confidence intervals.

(Entandophragma utile, Manilkara mabokeensis, and Myrianthus arboreus) and for six of the seven seed augmentation densities (0-500 times ambient seed rain). In total, we caged 18 quadrats per station ( $N=1134$ caged quadrats). We were limited to caging only three species because of the difficulty of carrying cages to remote forest sites. Cages consisted of $0.75 \mathrm{~m}$ high wooden frames covered by $13-\mathrm{mm}$ wire netting that protected the quadrats from terrestrial vertebrate predators, such as rodents, duikers, and forest pigs.

To examine the effect of hunting and logging on seed predation and seedling predation/herbivory, we fitted and evaluated generalized linear mixed models (GLMMs) to: (1) the number of seeds that failed to recruit as a function of the number of seeds added to a given quadrat; and (2) the number of seedlings that died as a function of the maximum number of emerged seedlings. We included seed augmentation level, forest type, and the caging treatment as explanatory variables, while species, site, and species-by-site were included as random effects. The random effects quantify variation in seed predation and seedling mortality among sites and species, and the species-by-site interaction examines the degree to which they depend on site identity. We fit all models with a binomial error distribution and a logit-link, using Laplace approximation (lme4 package) for maximum likelihood estimation of the parameters and testing the statistical significance of fixed effects with Wald Z statistics (Bolker et al., 2009). All statistical analyses were performed in R 2.7.2 (R Development Core Team, 2005).

\subsection{Adult forest composition and above-ground biomass}

To test for potential differences in forest composition and structure that may have resulted from sustained differences in vertebrate community structure and ecological processes, we set up 101 -ha plots in each forest type. Within each of the 30 forest plots, we tagged, measured, mapped and identified to species all trees greater than $10 \mathrm{~cm}$ dbh. Total above-ground biomass (AGB) of each tree was estimated using Chave et al.'s (2005) allometric equation that incorporates tree diameter and wood density, using published wood density estimates for trees harvested in Africa (Zanne et al., 2009). For unidentified species, we applied the mean wood density for each plot weighted by the number of trees from each plot (Lewis et al., 2009).

\subsection{Statistical analyses}

We compare values of seed rain, biomass, species, basal area, and wood density among our forest types (Results and Table 1). For each comparison we tested for normality, using non-parametric tests (Kruskal Wallis and Wilcoxon Rank Sum) when our data failed to fit a normal distribution. To test for differences in mean plot wood densities across DBH size categories and forest types, we employed Tukey's Honest Significant Difference to create a set of confidence intervals on the differences between the mean densities in each forest type.

\section{Results}

\subsection{Seed rain abundance and seed dispersal patterns}

The mean seed rain density per year was 340.3 seeds $\mathrm{m}^{-2}$ $(S D=943.2)$. Seed rain density was lowest in the hunted, logged forest ( 144.5 seeds $\left.\mathrm{m}^{-2}, \mathrm{SD}=140.2\right)$, then the logged only forest ( 361.4 seeds $\mathrm{m}^{-2}, \mathrm{SD}=1153.9$ ), and highest in the undisturbed forest $\left(515.0\right.$ seeds $\left.\mathrm{m}^{-2}, 1156.9\right)$. The density of Ficus seeds, however, dictated this trend: plots with Ficus had extremely high seed densities relative to plots without Ficus. Annual seed densities excluding Ficus were much lower (hunted $=95.2$ seeds $\mathrm{m}^{-2}$, logged only $=66.1$ seeds $\mathrm{m}^{-2}$, undisturbed $=75.8$ seeds $\mathrm{m}^{-2}$ ). There were no significant differences in densities of wind-dispersed seeds (ANOVA: $F_{2,27}=0.533, P=0.593$ ), or large, mammal-dispersed seeds (Kruskall-Wallis: $\chi^{2}=0.808, \mathrm{df}=2, P=0.667$ ) across the sites or between hunted and unhunted plots (wind-dispersed $t$-test: $t=0.924, \mathrm{df}=28, P=0.364$; large seeds Wilcoxon Rank Sum: $W=116, P=0.501)$.

From the seed trap data, we modeled the seed shadows of nine mammal-dispersed tree species in logged and unlogged forests and hunted and unhunted forest. Across all nine species, the correlation between the predicted data and observed data was $0.33(\mathrm{SD}=0.20)$ for hunted forests and $0.36(S D=0.20)$ for undisturbed forest. For five of nine species, the mean dispersal distance was farther in logged than unlogged forest (Fig. 2). The mean dispersal distance in logged forest was $15.6 \mathrm{~m}$ compared to $12.1 \mathrm{~m}$ in unlogged forest. For six of the nine species, the mean dispersal distance was farther in unhunted than hunted forest. The mean dispersal distance in 
Table 1

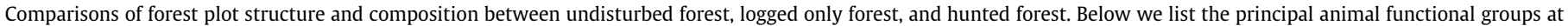
the study site. Species densities for each forest type can be found in Table 1 in Poulsen et al. (2011).

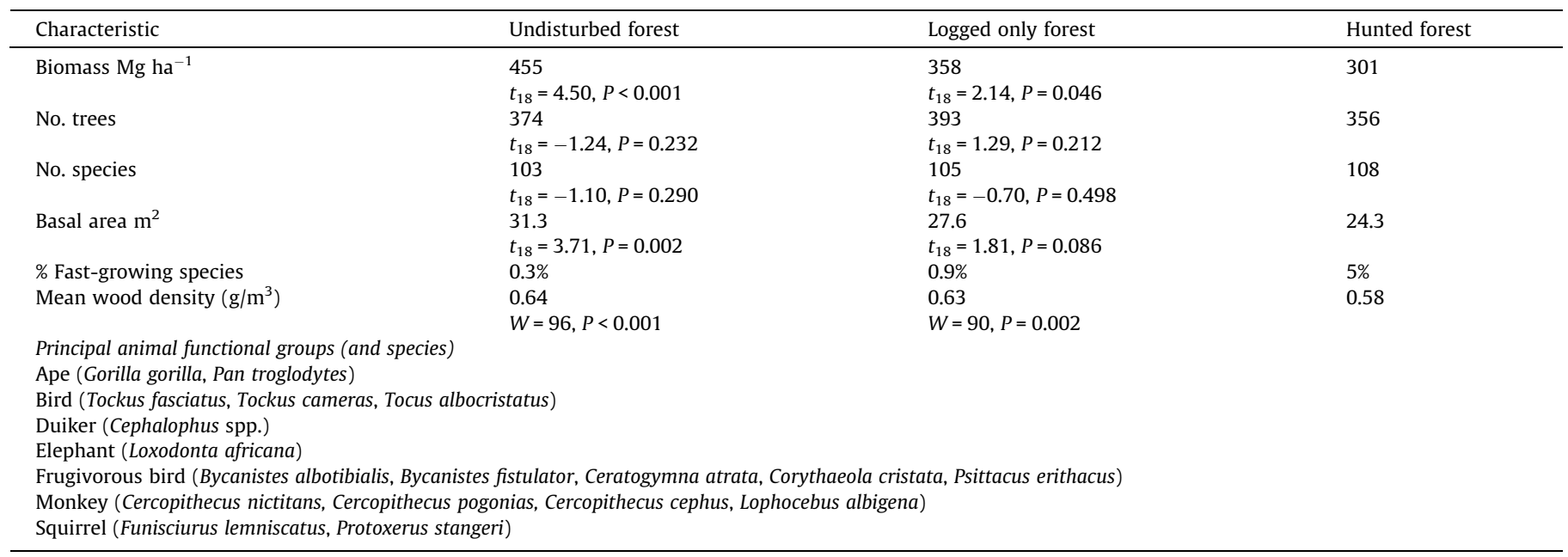

hunted forest $(11.6 \mathrm{~m})$ was $22 \%$ lower than unhunted forest (14.9 m; Fig. 3).

\subsection{Seed predation, herbivory, and seedling recruitment}

Across all plots, the majority of seeds of all five species in uncaged quadrats failed to germinate into seedlings, with $76.9 \%$ seed failure in hunted forest, $84.6 \%$ in logged only forest, and $74.5 \%$ in undisturbed forest. Of the seedlings that recruited, mortality after two years was $89.4 \%$ in hunted forest, $93.9 \%$ in logged only forest, and $93.7 \%$ in undisturbed forest. Seed mortality did not vary strongly with forest type $\left(\right.$ AIC $_{\text {No }}$ Site Effect $=1247$, $\mathrm{AIC}_{\text {Site Effect }}=1247$ ); whereas seedling mortality was significantly lower in hunted forest leading to greater seedling survival to two years than in the other forest types $\left(\mathrm{AIC}_{\mathrm{No}}\right.$ site effect $=775$,
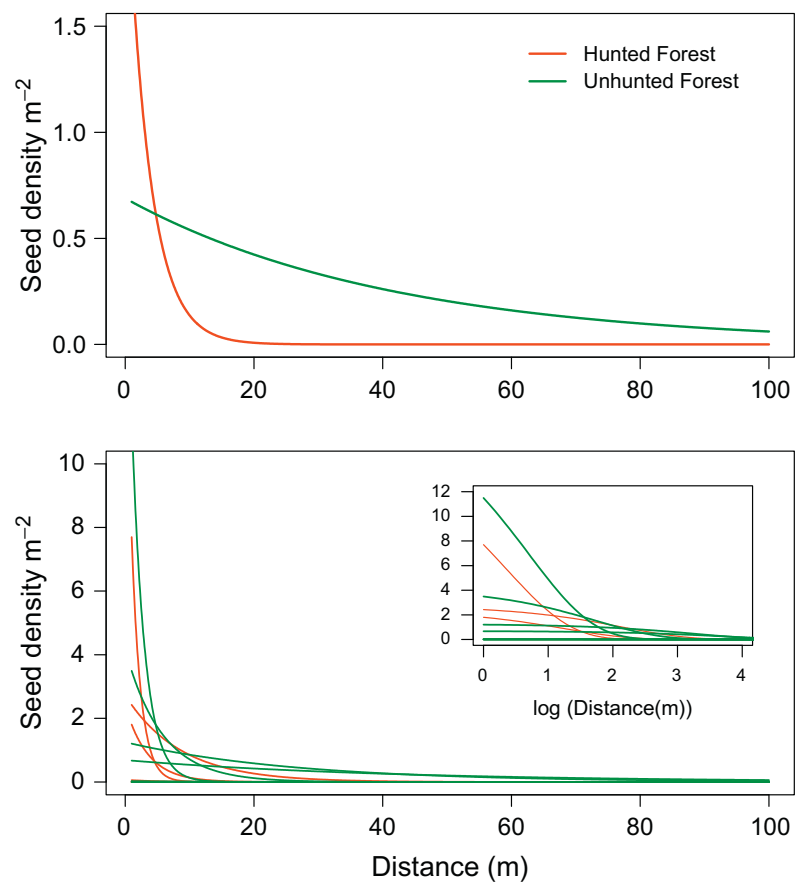

Fig. 3. Seed shadows of (top) Manilkara mabokeensis, and (bottom) nine animaldispersed tree species, in hunted forest (dashed lines) and unhunted forest (black lines).
AIC $\left._{\text {Site Effect }}=764\right)$. The odds of seedling mortality were 35 times greater in logged only forest $(Z=3.31, P<0.001)$ and 48 times greater in undisturbed forest $(Z=4.41, P<0.001)$ than in hunted forest.

Seed and seedling mortality in uncaged quadrats could be attributable to pathogens, invertebrates, and other unmeasured environmental factors; therefore we compared seed and seedling mortality in caged and uncaged quadrats to isolate the effects of seed predation and herbivory by vertebrates. Caging quadrats from vertebrate predators resulted in higher per seedling recruitment in hunted forest (11.2\%), logged forest (8.1\%) and undisturbed forest $(5.8 \%)$. Rates of seed predation were significantly lower in caged quadrats compared to uncaged quadrats (odds $=0.915, Z=-4.21$, $P<0.001$ ). There were no significant differences in seed predation with level of seed augmentation (odds $=0.989, \quad Z=-1.397$, $P=0.163$ ) or between hunted and unhunted forest types (logged only forest: odds $=1.12, Z=1.57, P=0.116$; undisturbed forest: odds $=1.01, Z=0.16, P=0.871)$. Caging quadrats resulted in slightly higher per seedling survival in hunted forest (6.3\%), logged forest $(5.1 \%$ ) and undisturbed forest (4.5\%). Rates of herbivory were not significantly higher with level of seed augmentation (odds $=1.02, Z=1.93, P=0.233$ ), but were significantly lower in caged quadrats (odds $=0.87, Z=-3.52, P<0.001$ ) and in hunted forest compared to unhunted forest types (logged only forest: odds $=1.15, Z=2.281, P=0.022$; undisturbed forest: odds $=1.23$, $Z=3.39, P<0.001)$.

\subsection{Forest structure and composition}

Average forest biomass was significantly lower in hunted forest (301 $\mathrm{Mg} \mathrm{ha}^{-1}$ ) compared to both logged forest (357 $\mathrm{Mg} \mathrm{ha}^{-1}$ ) and undisturbed forest (455 $\mathrm{Mg} \mathrm{ha}^{-1}$; Fig. 2). Whereas the effect of logging (21.5\% lower biomass in logged than undisturbed forest) is due to timber extraction, the drivers of the effect of hunting (15.7\% lower biomass in hunted than logged forest) are less obvious and cannot be explained by a difference in tree abundance, species abundance, or basal area (Table 1). But hunted forest contained a higher percentage of fast-growing, pioneer species. Accordingly, average tree wood density of the hunted forest (0.58) was significantly lower than the logged forest (0.63; Table 1$)$.

To evaluate whether the lower wood density could have been a result of changes in the strengths of ecological processes occurring over the last 35 years, we tested whether mean wood density in hunted forest was significantly lower across four tree diameter 


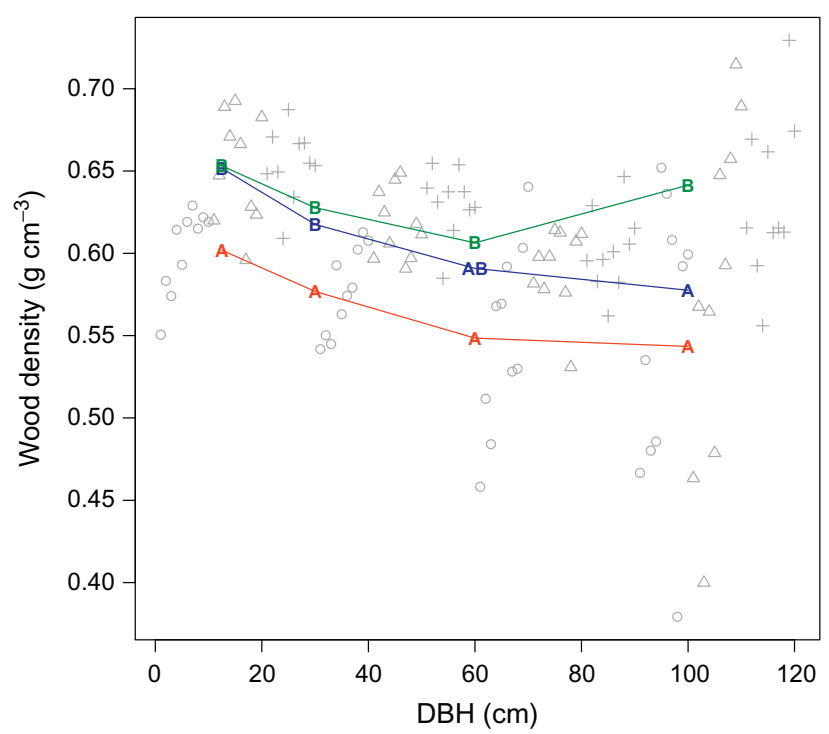

Fig. 4. Differences in mean wood density across the forest plots for hunted (red), logged only (blue), and undisturbed forest (green). Gray symbols in background demonstrate the mean plot wood density for each of the forest types. Letters denote significant differences between forest types in mean wood density across different DBH categories $(<15 \mathrm{~cm}, 15-40 \mathrm{~cm}, 40-80 \mathrm{~cm},>80 \mathrm{~cm}$ ). (For interpretation of the references to color in this figure legend, the reader is referred to the web version of this article.)

classes $(<15 \mathrm{~cm}, 20-40 \mathrm{~cm}, 40-80,>80 \mathrm{~cm})$. Given the relatively short timeframe for hunting effects to accumulate, we reasoned that any resulting changes in ecological processes could only have affected smaller diameter classes of trees. Assuming a maximum $1-2 \mathrm{~cm} \mathrm{y}^{-1} \mathrm{dbh}$ increment (Lewis et al., 2009), we would expect any differences in wood densities above $35-40 \mathrm{~cm}$ to be due to some environmental factor and not the loss of large mammals. We found that wood densities were significantly lower in hunted than unhunted forest for the $15 \mathrm{~cm}$ diameter class ( $\Delta$ hunted and logged only $=0.037,95 \% \mathrm{CI}=[0.008,0.068] ; \Delta$ hunted and undisturbed $=0.039,95 \% \mathrm{CI}=[0.009,0.069])$, and the $20-40 \mathrm{~cm}$ diameter class ( $\Delta$ hunted and logged only $=0.042,95 \% \mathrm{CI}=[0.017,0.067] ; \Delta$ hunted and undisturbed $=0.055,95 \% \mathrm{CI}=[0.030,0.080]$; Fig. 4$)$. But at the larger size classes, there were no significant differences between hunted and logged only forest at the $40-80 \mathrm{~cm}$ ( $\Delta$ hunted and logged only $=0.021,95 \% \mathrm{CI}=[-0.008,0.051])$ or the $>80 \mathrm{~cm}$ diameter class $(\Delta$ hunted and logged only $=0.017,95 \%$ $\mathrm{CI}=[-0.065,0.099]$; Fig. 4$)$. Timber harvest likely contributed to differences in mean wood density at the $40-80 \mathrm{~cm}$ ( $\Delta$ hunted and undisturbed $=0.033,95 \% \mathrm{CI}=[0.003,0.062]$ ) and $>80 \mathrm{~cm}$ diameter classes ( $\Delta$ hunted and undisturbed $=0.087,95 \%$ $\mathrm{CI}=[0.005,0.170] ; \Delta$ logged only and undisturbed $=0.079,95 \%$ $\mathrm{CI}=[0.002,0.158]$; Fig. 4).

\section{Discussion}

In a Central African forest, we found evidence that forest impacted by both hunting and logging had shorter seed dispersal distances for mammal-dispersed trees and lower rates of seedling herbivory than logged only forest and undisturbed forest. The hunted forest was also characterized by significantly lower aboveground biomass than logged only or undisturbed forest. We evaluate the hypothesis that the interruption of plant-animal interactions might alter the species composition of the forest over time, resulting in a higher proportion of fast-growing, low wood density tree species and diminishing the long-term potential for carbon storage.

\subsection{Ecological erosion and plant-animal interactions}

Complete defaunation is not prerequisite for changes in ecological processes. We found no evidence of local extirpation of species at our study sites: even the hunted and logged sites still contained a full complement of medium- and large-bodied mammal species, but at significantly lower densities than logged only or undisturbed sites. Therefore, it is the strength of ecological processes like seed dispersal and herbivory that matter, not merely their presence or absence.

Hunting levels that typify those of most Central African forests altered seed dispersal patterns of mammal-dispersed trees by reducing dispersal distances, but only by $3.3 \mathrm{~m}$ on average. Even though this represents a $22 \%$ reduction in dispersal distance, it is difficult to imagine that it would strongly affect forest composition. Our trap-based design is unlikely to have captured the full reduction in dispersal distances, as we did not quantify seed dispersal by terrestrial mammals. Furthermore, seed trap studies, which focus on the local neighborhood of the tree, tend to underestimate long distance dispersal by animals (e.g., Holbrook and Smith, 2000; Russo et al., 2006). Thus, we suspect that the real reduction in seed dispersal distances is greater than estimated by our models and might be strong enough to influence the composition of the seedling and sampling communities. By redistributing seeds of a monkey-dispersed tree species in patterns that simulated defaunation, Poulsen et al. (2012) demonstrated that loss of dispersal would reduce seedling survival to one year by $78 \%$ compared to natural dispersal patterns. In a truly defaunated forest, Terborgh et al. (2008) found the loss of dispersal function allowed species dispersed abiotically and by small birds and mammals to replace those dispersed by large birds and mammals (Terborgh et al., 2008).

Hunted forest had significantly lower rates of seedling herbivory than the other forest types, resulting in higher levels of seedling survival. We attribute the reduced rates of herbivory to the disproportionate loss of duikers and forest pigs that are preferred prey for hunters (Fa et al., 2005; Poulsen et al., 2009). Herbivory by vertebrates, more than environmental characteristics, determined rates of seedling recruitment and survival at our site (Clark et al., 2012), suggesting that plant species adapted to avoid or recover from herbivory have a demographic advantage. Lower herbivory pressure on plants should reduce the importance of these traits, potentially favoring the recruitment of fast-growing species that allocate few resources towards anti-herbivore defenses (Fig. 5).

\subsection{Altered plant-animal interactions and the plant community}

We predict that reductions in the dispersal of mammal-dispersed species will result in greater recruitment of small-seeded, abiotically dispersed seeds (Terborgh et al., 2008); whereas reductions in rates of herbivory will favor fast-growing, light-loving species that are generally characterized as having fewer herbivore defenses and lower wood density (Slik, 2005; Lewis, 2006). A few studies have found a positive relationship between seed size and wood density, suggesting that reduced dispersal of large-seeded plants by animals would also favor low wood density species (Slik, 2005; Wright et al., 2007a,b; Queenborough et al., 2009). Interestingly, these predicted patterns match what we find in our surveys of forest community structure. As expected, we found the average biomass of logged forest to be significantly lower than unlogged forest; but we were surprised that hunted forest had $15.7 \%$ less biomass than logged only forest. Similar timber extraction practices and intensities were employed throughout the site (Paget, pers. comm.), which led us to look for other explanations for this difference in aboveground biomass. We hypothesize that over 


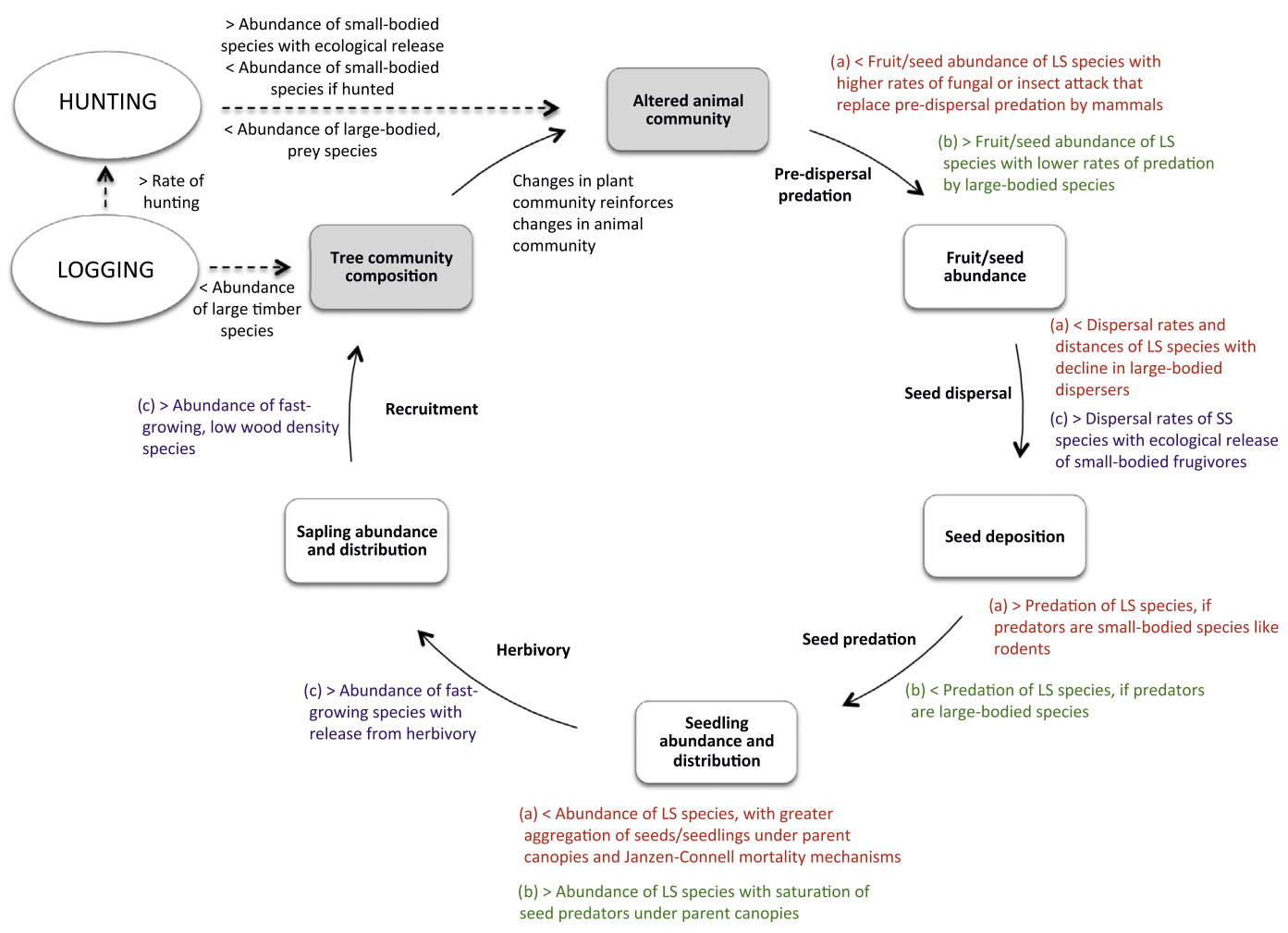

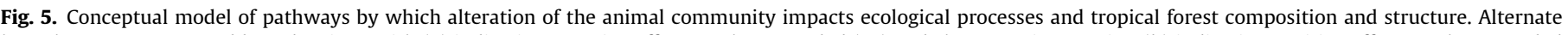

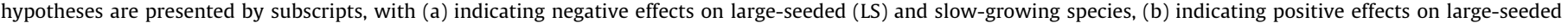
species, and (c) indicating positive effects on small-seeded (SS) and fast-growing species.

35 years of hunting the combination of lower rates of dispersal of large-seeded species and lower rates of herbivory has favored the regeneration and growth of fast-growing tree species with low wood density. The key mechanism may be relaxation of browsing by mammals on large seedlings and saplings. By releasing poorly defended, fast-growing plant species from herbivore pressure, hunting may lead to a lower proportion of slow-growing, high wood density tree species in the plant community. This humananimal mediated trend, which we term the forest herbivore hypothesis, may diminish the forest's long-term carbon storage potential.

\subsection{Caveats and quantifying the effects of ecological erosion}

The aim of this paper was to assess the cascading effects of hunting and logging on ecological processes and to predict the potential consequences for forest structure. Our study has several limitations. We draw conclusions about the strength of seed dispersal, seed predation and herbivory from a low number of species relative to the species richness of the forest. Our study design is also pseudoreplicated in the sense that sites impacted by the same disturbance type are geographically grouped together (Hurlbert, 1984; see Poulsen et al., 2011). It is therefore possible that the difference in biomass between the hunted and logged only forest is due to environmental factors or different intensities of timber extraction of which we are not aware. The trends we found in this study need to be studied in greater detail and in additional forest sites.

Hunting, whether it results in decreased abundances of large vertebrates or complete defaunation, is having an enormous impact on the majority of tropical forests worldwide. To predict its consequences for forests, we need to know a great deal more about how the strengths of ecological processes vary across a gradient of faunal loss, the extent to which vertebrate species are redundant in their functional roles, and the consequences of ecological erosion for ecosystem services (protein provision, habitat provision, carbon storage, nutrient cycling, etc.). These questions should be addressed through a combination of natural experiments and controlled manipulations that measure ecological processes in relation to known animal abundance or hunting intensity. Such experiments should be conducted with a focus on plant traits (seed size, wood density, specific leaf area, tree height) that render some species more susceptible to the effects of defaunation than others. The ultimate experiment would be a replicated exclosure experiment at the scale that large forest vertebrates operate to directly test the consequences of defaunation and ecological erosion (e.g., Goheen et al., 2013).

\subsection{Avoiding defaunation and ecological erosion}

In tropical forests today, wildlife abundance is often more closely correlated with patterns of hunting than with factors such as forest type, the area of the habitat, or its protected status (Woodroffe and Ginsberg, 1998). More often than not, the depletion of wildlife is the consequence of deforestation and forest degradation by major industries and economic globalization, rather than subsistence hunting by rural communities (Butler and Laurance, 2008; Clark and Poulsen, 2012). If a strong link is rigorously established between the loss of wildlife and changes in forest composition and structure that reduce timber yields or carbon stocks, both industry and government are likely to become more active in the enforcement of hunting laws. Partnerships with logging (Berry et al., 2010; Clark et al., 2009) and oil concessionaires (Laurance et al., 2006) have sometimes proven to be an effective financial and technical strategy for protecting wildlife without denying nations the economic benefits of extractive industries. 
Not all tropical forests can or will be protected from defaunation, and for some it is too late; thus we need to redouble our efforts to understand the consequences of ecological erosion. The enormous gaps in our understanding of the process make it both an exciting field of study and an urgent conservation problem.

\section{Acknowledgements}

We thank the Government of Congo and its Ministries of Forestry Economy and Scientific Research for permission to conduct this research and the Wildlife Conservation Society and the Buffer Zone Project (PROGEPP) for their logistical support. JRP and CJC were supported by a University of Florida Presidential fellowship (JRP), a School of Natural Resources and Environment alumni fellowship (CJC), and Environmental Protection Agency Science to Achieve Results (STAR) fellowships (91630801-0 [JRP] and 91643301-0 [CJC]). TMP was supported by a grant from the National Science Foundation (NSF DEB 1149980). E. Elenga and G. Abeya, O. Mbani, Y. Nganga, M. Mokoke, and I. Loungouba contributed to data collection. Special thanks to Mauro Galetti and Rodolfo Dirzo for organizing the 2012 ATBC Symposium on the trophic downgrading of tropical terrestrial ecosystems that inspired this paper.

\section{Appendix A. Supplementary material}

Supplementary data associated with this article can be found in the online version, at http://dx.doi.org/10.1016/j.biocon.2013.03. 021. These data include Google maps of the most important areas described in this article.

\section{References}

Beckman, N.C., Muller-Landau, H.C., 2007. Differential effects of hunting on predispersal seed predation and primary and secondary seed removal of two neotropical tree species. Biotropica 39, 328-339.

Berry, N.J., Phillips, O.L., Lewis, S.L., Hill, J.K., Edwards, D.P., Tawatao, N.B., Norhayati, A., Magintan, D., Khen, C.V., Maryati, M., Ong, R.C., Hamer, K.C., 2010. The high value of logged tropical forests: lessons from northern Borneo. Biodivers. Conserv. 19, 985-997.

Bolker, B.M., Brooks, M.E., Clark, C.J., Geange, S.W., Poulsen, J.R., Stevens, M.H.H., White, J.S.S., 2009. Generalized linear mixed models: a practical guide for ecology and evolution. Trends Ecol. Evol. 24, 127-135.

Brncic, T.M., Willis, K.J., Harris, D.J., Washington, R., 2007. Culture or climate? The relative influences of past processes on the composition of the lowland Congo rainforest. Philos. Trans. Roy. Soc. B 362, 229-242.

Brodie, J.F., Helmy, O.E., Brockelman, W.Y., Maron, J.L., 2009. Bushmeat poaching reduces the seed dispersal and population growth rate of a mammal-dispersed tree. Ecol. Appl. 19, 854-863.

Brook, B.W., Sodhi, N.S., Ng, P.K.L., 2003. Catastrophic extinctions follow deforestation in Singapore. Nature 424, 420-423.

Butler, Rhett A., 2013. Mongabay.com. <http://www.mongabay.com/> (Retrieved 01.02.13).

Butler, R.A., Laurance, W.F., 2008. New strategies for conserving tropical forests. Trends Ecol. Evol. 23, 469-472.

Byrd, R.H., Lu, P., Nocedal, J., Zhu, C., 1995. A limited memory algorithm for bound constrained optimization. SIAM J. Sci. Comput. 16, 1190-1208.

Chave, J., Andalo, C., Brown, S., Cairns, M.A., Chambers, J.Q., Eamus, D., Fölster, H., Fromard, F., Higuchi, N., Kira, T., Lescure, J.P., Nelson, B.W., Ogawa, H., Puig, H., Riéra, B., Yamakura, T., 2005. Tree allometry and improved estimation of carbon stocks and balance in tropical forests. Oecologia 145, 87-99.

Congolaise Industrielle des Bois (CIB), 2006. Plan d'amenagement de l'unité forestière d'aménagement de Kabo (2005-2034). Ministry of Forest Economy, Brazzaville, Republic of the Congo.

Clark, J.S., 1998. Why trees migrate so fast: confronting theory with dispersal biology and the paleorecord. Am. Naturalist 152, 204-224.

Clark, C.J., Poulsen, J.R. (Eds.), 2012. Tropical Forest Conservation and Industry Partnership: An Experience from the Congo Basin. Blackwell Publishing, Oxford, UK.

Clark, C.J., Poulsen, J.R., Malonga, R., Elkan, P.W., 2009. Can wildlife management in logging concession extend the "conservation estate" of tropical forests? Conserv. Biol. 23, 1281-1293.

Clark, C.J., Poulsen, J.R., Levey, D.J., 2012. Vertebrate herbivory impacts seedling recruitment more than niche partitioning, distance- or density-dependent mortality. Ecology 93, 554-564.
Dirzo, R., Miranda, A., 1991. Altered patterns of herbivory and diversity in the forest understory: a case study of the possible consequences of contemporary defaunation. In: Price, P.W., Lewinsohn, T.M., Fernandes, G.W., Benson, W.W. (Eds.), Plant-Animal Interactions: Evolutionary Ecology in Tropical and Temperate Regions. Wiley \& Sons, New York, New York, pp. 273-287.

Fa, J.E., Currie, D., Meeuwig, J., 2003. Bushmeat and food security in the Congo Basin: linkages between wildlife and people's future. Environ. Conserv. 30, 71-78.

Fa, J.E., Ryan, S.F., Bell, D.J., 2005. Hunting vulnerability, ecological characteristics and harvest rates of bushmeat species in Afrotropical forests. Biol. Conserv. 121, 167-176.

Galetti, M., Donatti, C.I., Pires, A.S., Guimarães Jr., P.r., Jordano, P., 2006. Seed survival and dispersal of an endemic Atlantic forest palm: the combined effects of defaunation and forest fragmentation. Bot. J. Linn. Soc. 151, 141-149.

Goheen, J.R., Palmer, T.M., Charles, G.K., Helgen, K.M., Kinyua, S.N., Maclean, J.E., Young, H.S., Pringle, R.M., 2013. Piecewise disassembly of a large-herbivore community across a rainfall gradient: the UHURU experiment. PLoS ONE 8 (2), e55192. http://dx.doi.org/10.1371/journal.pone.0055192.

Hilborn, R., Mangel, M., 1997. The Ecological Detective: Confronting Models with Data. Princeton University Press, Princeton, NJ.

Holbrook, K.M., Loiselle, B.A., 2009. Dispersal in a Neotroipcal tree, Virola flexuosa (Myristicaceae): does hunting of large vertebrates limit seed removal? Ecology 90, 1449-1455.

Holbrook, K.M., Smith, T.B., 2000. Seed dispersal and movement patterns in two species of Ceratogymna hornbills in a West African tropical lowland forest. Oecologia 125, 249-257.

Hurlbert, S.H., 1984. Pseudoreplication and the design of ecological field experiments. Ecol. Monogr. 54, 187-211.

Kurten, $\mathrm{X}$, this issue. Biological Conservation.

Lanfranchi, R., Ndanga, J., Zana, H., 1998. New carbon 14C datings of iron metallurgy in the Central African dense forest. In: Eves, H.E., Hardin, R., Rupp, S. (Eds.), Resource use in the Trinational Sangha river region of Equatorial Africa: histories, knowledge forms, and institutions. Yale School of Forestry and Environmental Studies, New Haven, Connecticut, USA, pp. 41-50.

Laurance, W.F., Croes, B.M., Tchignoumba, L., Lahm, S.A., Alonso, A., Lee, M.E., Campbell, P., Ondzeano, C., 2006. Impacts of roads and hunting on central African rainforest mammals. Conserv. Biol. 20, 1251-1261.

Lewis, S.L., 2006. Tropical forests and the changing earth system. Philos. Trans. Roy. Soc. B-Biol. Sci. 361, 195-210.

Lewis, S.L., Lopez-Gonzalez, G., Sonke, B., Affum-Baffoe, K., Baker, T.R., Ojo, L.O., Phillips, O.L., Reitsma, J.M., White, L., Comiskey, J.A., Djuikouo, M.N., Ewango, C.E.N., Feldpausch, T.R., Hamilton, A.C., Gloor, M., Hart, T., Hladik, A., Lloyd, J., Lovett, J.C., Makana, J.R., Malhi, Y., Mbago, F.M., Ndangalasi, H.J., Peacock, J., Peh, K.S.H., Sheil, D., Sunderland, T., Swaine, M.D., Taplin, J., Taylor, D., Thomas, S.C., Votere, R., Woll, H., 2009. Increasing carbon storage in intact African tropical forests. Nature 457, 1003-1007.

Muller-Landau, H.C., 2007. Predicting the long-term effects of hunting on plant species composition and diversity in tropical forests. Biotropica 39, 385-392.

Muller-Landau, H.C., Wright, S.J., Calderon, O., Condit, R., Hubbell, S.P., 2008 Interspecific variation in primary seed dispersal in a tropical forest. J. Ecol. 96, 653-667.

Peres, C.A., Palacios, E., 2007. Basin-wide effects of game harvest on vertebrate population densities in Amazonian forests: Implications for animal-mediated seed dispersal. Biotropica 39, 304-315.

Poulsen, J.R., Clark, C.J., Mavah, G., Elkan, P.W., 2009. Bushmeat supply and consumption in a tropical logging concession in northern Congo. Conserv. Biol. 23, 1597-1608.

Poulsen, J.R., Clark, C.J., Bolker, B.M., 2011. Decoupling the effects of logging and hunting on an Afrotropical animal community. Ecol. Appl. 21, 1819-1836.

Poulsen, J.R., Clark, C.J., Bolker, B.M., 2012. Experimental manipulation of seed shadows of a tropical tree determines drivers of recruitment. Ecology 93, 500510 .

Queenborough, S.A., Mazer, S.J., Vamosi, S.M., Garwood, N.C., Valencia, R., Freckleton, R., 2009. Seed mass, abundance and breeding system among tropical forest species: do dioecious species exhibit compensatory reproduction or abundances? J. Ecol. 97, 555-566.

$\mathrm{R}$ Development Core Team, 2005. R: a language and environment for statistical computing. R Foundation for Statistical Computing, Vienna, Austria.

Ribbens, E., Silander, J.A., Pacala, S.W., 1994. Seedling recruitment in forests calibrating models to predict patterns of tree seedling dispersion. Ecology 75, 1794-1806.

Robinson, J.G., Redford, K.H., Bennett, E.L., 1999. Wildlife harvest in logged tropical forests. Science 284, 595-596.

Russo, S.E., Portnoy, S., Augspurger, C.K., 2006. Incorporating animal behavior into seed dispersal models: implications for seed shadows. Ecology 87, 3160-3174.

Sagnard, F., Pichot, C., Dreyfus, P., Jordana, P., Fady, B., 2007. Modelling seed dispersal to predict seedling recruitment: recolonization dynamics in a plantation forest. Ecol. Model. 203, 464-474.

Slik, J.W.F., 2005. Assessing tropical lowland forest disturbance using plant morphological and ecological attributes. For. Ecol. Manage. 205, 241-250.

Terborgh, J., Nunez-Iturri, G., Pitman, N.C.A., Valverde, F.H.C., Alvarez, P., Swamy, V., Pringle, E.G., Paine, C.E.T., 2008. Tree recruitment in an empty forest. Ecology 89, 1757-1768.

Vanthomme, H., Bellé, B., Forget, P.-M., 2010. Bushmeat hunting alters recruitment of large-seeded plant species in Central Africa. Biotropica 42, 672-679.

Wilkie, D.S., Shaw, E., Rotberg, F., Morelli, G., Auzel, P., 2000. Roads, development, and conservation in the Congo Basin. Conserv. Biol. 14, 1614-1622. 
Woodroffe, R., Ginsberg, J.R., 1998. Science 280, 2126-2128.

Wright, S.J., Zeballos, H., Dominguez, I., Gallardo, M.M., Moreno, M.C., Ibanez, R., 2000. Poachers alter mammal abundance, seed dispersal and seed predation in a Neotropical forest. Conserv. Biol. 14, 227-239.

Wright, I.J., Ackerly, D.D., Bongers, F., Harms, K.E., Ibarra-Manriquez, G., MartinezRamos, M., Mazer, S.J., Muller-Landau, H.C., Paz, H., Pitman, N.C.A., Poorter, L., Silman, M.R., Vriesendorp, C.F., Webb, C.O., Westoby, M., Wright, S.J., 2007 a. Relationships among ecologically important dimensions of plant trait variation in seven Neotropical forests. Ann. Bot. 99, 1003-1015.
Wright, S.J., Hernandéz, A., Condit, R., 2007b. The bushmeat harvest alters seedling banks by favoring lianas, large seeds, and seeds dispersed by bats, birds and wind. Biotropica 39, 363-371.

Zanne, A.E., Lopez-Gonzalez, G., Coomes, D.A., Ilic, J., Jansen, S., Lewis, S.L., Miller, R.B., Swenson, N.G., Wiemann, M.C., Chave, J. 2009. Global Wood Density Database. Dryad. <http://hdl.handle.net/10255/dryad.235>. 